\title{
037 \\ In vitro shoot tip culture of Red Sandalwood (Pterocarpus santalinus L.)
}

\author{
P S Warakagoda, D L C Kumari and S Subasinghe \\ Department of Crop Science, University of Ruhuna, Sri Lanka
}

Red Sandalwood (Pterocarpus santalinis L.) is an endangered woody plant species of family Leguminosae with high medicinal value. According to some assessments (Arunakumara et al, 2005) trees of this species are available in Southern parts of Sri Lanka. However seed propagation of red sandalwood has some constraints like low germination of seeds. dormancy of seeds. fungal growth inside the seed coat, scarcity of plants, seasonal fruit bearing habit of trees (Kumarasinghe et al, 2003). Therefore in vitro shoot tip culture can be applied as an alternative propagation technique for conservation and multiplication of Red sandalwood plants in Sri Lanka.

Shoot tips were excised from field grown and plant house grown plants. Experiments were carried out to identify proper surface sterilization procedures for explants and to identify proper establishment media for sterilized explants. $\mathrm{NaOCl}(10,15.20 \%)$ with different exposure times (10.15.20 minutes) were tested and Murashige and Skoog (MS) and Mccown woody plant (WPM)) media were used as establishment media with and without activated charcoal $(1 \mathrm{~g} / 1)$. Completely Randomized Design (CRD) with twenty replicates was applied for the study.

Results revealed that, usage of $10 \% \mathrm{NaOCl}$ for 20 minutes exposure time showed highest survival percentage $(100 \%)$ for shoot tips detected from plantlets grown in the plant house where contamination were controlled up to zero level. Promotion of auxiliary buds within two weeks after culture initiation and appearance of new leaves within a month were observed in survived cultures. For explants detected from field grown plants $10 \% \mathrm{NaOCl}$ for 15 minutes exposure time showed $70 \%$ survival where promotion of auxiliary buds within two weeks time and appearance of new leaves within a month was observed. Among the two media tested both MS medium and WPM medium were well suited for culture establishment of plant house derived explants where $1.0 \mathrm{gl}^{-1}$ activated charcoal was incorporated or not as an absorbent. However MS medium with $1.0 \mathrm{gl}^{-1}$ activated charcoal was the best medium for explants from field grown plants. Of well established explants, $10 \%$ showed adventitious root formation in MS charcoal free medium. Immature stem cuttings showed best growth performances where semi hard wood stem cuttings showed enlargement of stem diameter and callus formation at cut ends.

Further studies are needed to identify proper shoot proliferation and rooting media for established shoot tips of red sandalwood. Finally there is a need to identify a suitable acclimatization procedure for in vitro derived plantlets to resume independent growth in the field.

\section{8 \\ Screening of coconut (Cocos nusifera L.) for drought tolerance \\ W G D Lakmini', N P A D Nainanayake ${ }^{2}$ and W A J M De Costa ${ }^{3}$ \\ 'Department of Crop Science, University of Ruhuna, Sri Lanka \\ ¿Plant Physiology Division, Coconut Research institute of Sri Lanka, Lunuwilla, Sri Lanka \\ 'Department of Crop Science, University of Peradeniya, Sri Lanka}

Drought causes a substantial reduction in national yield of coconut and also a loss of coconut palms in severe droughts thus resulting in serious economic consequences in the coconut industry in Sri Lanka. Therefore, it is a prime importance to identify some putative drought tolerant genotypes for the use in drought prone areas. The long generation and maturation periods of coconut restrict the selection of genotypes based on yield. Therefore, in this study the effects of drought on stomatal conductance $\left(g_{s}\right)$ and water potential $(\Psi)$ of four coconut genotypes (the accession Clovis $[C L]$ is believed to be tolerant to drought while the rest Dwarf Green [DG], Dwarf Brown [DB] and Cameron Red Dwarf [CRD] are sensitive) were measured to develop an index for stomatal performances (ISP) using ISP $=\sum_{x=1}^{t} X$. FX equation. Where, $t, X$ and $F$ are the number of genotypes, grade point obtained by the genotype for recordings of $g_{s}$ and $\Psi$ during drought and frequency of the corresponding grade point respectively. All palms were about 15 years of age and managed according to the recommended

Proceedings of the International Forestry and Environment Symposium 2006 of the

Department of Forestry and Environmental Science, University of Sri Jayewardenepura. Sri Lanka 